\title{
Beehive fence deters crop-raiding elephants
}

\author{
Lucy E. King ${ }^{1,2,3 *}$, Anna Lawrence ${ }^{3}$, Iain Douglas-Hamilton ${ }^{1,2}$ and Fritz Vollrath ${ }^{1,2}$ \\ ${ }^{1}$ Department of Zoology, University of Oxford, South Parks Road, Oxford, OX1 3PS, U.K., ${ }^{2}$ Save the Elephants, P.O. Box 54667, Nairobi O0200, \\ Kenya and ${ }^{3}$ Environmental Change Institute, University of Oxford, South Parks Road, Oxford, OX1 3QY, U.K.
}

\begin{abstract}
Previous work has shown that African elephants Loxodonta africana will avoid African honeybees Apis mellifera scutellata. Here we present results from a pilot study conducted to evaluate the concept of using beehives to mitigate elephant crop depredation. In Laikipia, Kenya, we deployed a 90-m fence-line of nine inter-connected hives, all empty, on two exposed sides of a square two-acre farm that was experiencing high levels of elephant crop depredation. Compared with a nearby control farm of similar status and size, our experimental farm experienced fewer raids and consequently had higher productivity. Socioeconomic indicators suggest that not only was the concept of a beehive fence popular and desired by the community but also that it can pay for its construction costs through the sale of honey and bee products. We are calling for experiments testing this concept of a 'guardian beehive-fence' to be conducted rigorously and scientifically in as wide a range of agricultural settings as possible to evaluate jointly its effectiveness and efficiency.
\end{abstract}

Key words: African elephants, beekeeping, behaviour, crop raiding, deterrents, human-elephant conflict

\section{Résumé}

Des travaux antérieurs ont montré que les éléphants africains Loxodonta africana évitent les abeilles africaines Apis mellifera scutellata. Nous présentons ici les résultats d'une étude pilote réalisée pour évaluer le concept consistant à utiliser des ruches pour réduire la destruction des cultures par les éléphants. A Laikipia, au Kenya, nous avons installé une barrière de $90 \mathrm{~m}$. de long composée de neuf ruches interconnectées, toutes vides, sur deux côtés exposés d'une ferme carrée de deux acres (arpents) dont les cultures subissaient une forte déprédation causée par les éléphants. Comparée à une ferme contrôle voisine, de

*Correspondence: E-mail: lucy.king@zoo.ox.ac.uk statut et de taille comparables, notre ferme expérimentale a subi moins de raids et a donc eu une meilleure productivité. Des indicateurs socioéconomiques suggèrent que non seulement le concept de barrière en ruches était populaire et souhaité par la communauté, mais qu'il peut même couvrir les frais de sa propre construction grâce à la vente de miel et autres produits dérivés. Nous sollicitons que des expériences soient faites pour tester ce concept de « clôture en ruches » de façon rigoureuse et scientifique, dans une gamme aussi étendue que possible d'installations agricoles, afin d'évaluer son efficacité et sa faisabilité.

\section{Introduction}

Elephants in Kenya are not confined to National Parks and Reserves (Douglas-Hamilton, Krink \& Vollrath, 2005). Hence, interactions with farmers, and specifically crop raiding by elephants targeting fields, pose serious social, political, economic and conservation problems in Kenya as it does in many other parts of Africa (Newmark, Manyanza \& Gamassa Deo-Gratias, 1994; Barnes, 1996; Hoare, 2000; Osborn \& Parker, 2002; Balfour et al., 2007). Accordingly, research efforts are now focused on finding effective farmer-managed deterrents that are both socially and economically suitable especially in 'conflict' zones where effective electric fences to separate humans from elephants are neither feasible nor affordable (Osborn \& Parker, 2003; Omondi, Bitok \& Kagiri, 2004).

Locals in and around our northern Kenyan study sites tell anecdotes of elephants being 'afraid' of bees. Vollrath \& Douglas-Hamilton (2002) experimentally tested this concept by deploying beehives in a frequently visited bush area and demonstrated that elephants avoid feeding on acacia trees hosting hives (both empty and full) of the African honeybee. Following this, King and colleagues further demonstrated in more detailed playback experiments using a recording of disturbed bee sounds that elephants associate bee-buzz with a threat and run away, a behaviour 
not observed in response to appropriate controls (King, Douglas-Hamilton \& Vollrath, 2007). Both studies strongly support the hypothesis that bees themselves, or even evidence of their presence such as empty hives or buzzing sounds, can be used to limit crop raiding by elephants. If indeed it were possible to use bees as an 'eco-deterrent' against elephant depredations, then this could have important socioeconomic implications. Not only would it diminish loss of farming income but would also add a diverse source of income through sales of bee products such as honey and wax (Bradbear, 2002).

Here we present results from a pilot study conducted to explore the deterrent capabilities of a unique beehive fence. Our two objectives were (i) to test the effectiveness of the new fence design and (ii) to assess stakeholder response and interest. In our experimental community, bee keeping was an established practice so we used a participatory monitoring framework to reveal individual and group reactions to the introduction of the novel technology of deploying bees to guard against elephants. Participation and inclusion in a project's decision-making foster commitment and accountability and often lead to a sense of empowerment and ownership (Kapoor, 2001; Hellin et al., 2008). Our monitoring was based on Franzel et al. (2002) Type 2 field trials where farmers and scientists collaborate on the execution of the trial but the researcher offers the new technology for trial and leads on the experimental design. We outline our participatory methods in detail as we consider informed and full participation a key element to this kind of study and hence important for any repeats aiming to test its validity. While our study is rather preliminary (a large-scale trial is underway at another location), its results are very encouraging. Hence, on requests from farmers and wildlife managers, we are presenting the specifics of the beehive fence design and its preliminary results to enable wider trials to be conducted by willing experimenters elsewhere on the continent.

\section{Materials and methods}

Our study was conducted in the 20,000 acre Ex-Erok community in the southern region of Laikipia, Kenya. The 9,700 $\mathrm{km}^{2}$ Laikipia plateau comprises a complex land use mosaic of large private and government cattle ranches, pastoral grazing lands and small holder farms. Historically a wildlife rich area, large mammals still roam freely throughout the district but with increases in human immigration and the proliferation of stronger boundary fences, elephants in particular are now competing for vital resources with local farmers. Beekeeping activities in the area are typically small scale using traditional hives, and honey is valued for both consumption and as a cash crop (Raina, 2000).

The Ex-Erok study was carried out with cooperation and assistance from rural farmers within the seventeen member strong Mwireri Beekeepers Group. The area had been identified in 2004 as a high-risk area for crop raiding (Graham, 2007; Graham \& Ochieng, 2008). After an introduction by Max Graham to the community, we conducted pretrial interviews with six different farmers across the community. Both their answers and observations of damaged fields confirmed the area's status as a high conflict zone for crop-raiding incidents by elephants.

Eight farmers from the Mwireri Beekeepers Group participated consistently during the development phase of the trial. These farmers represented approximately one-third of the households in the immediate trial area. Initially, two participatory activities were undertaken to help in designing the experimental trial. A calendar of the average year was discussed to highlight certain key activities relevant to the study. These included identifying planting, harvesting, rainy and dry seasons as well as the worst months for elephant crop raids. This calendar of seasonal activities identified the dry harvesting season of AugustSeptember as the best period to trial the beehive fence because of the prevalence of elephant raids during this time.

To select a site for the experimental trial of the beehive fence, these eight farmers created a map of their farming area. They drew symbols for each household, dominant land features (such as roads, dams, schools) and finally the movement patterns of elephants through the landscape. This map revealed that elephants living within the neighbouring cattle ranch frequently visited the community's water dam for an evening drink before entering the community lands for a night of crop raiding. The main route of elephant entrance from the dam into the village passed between two smallholder farms either side of the 'elephant highway', a phrase used by the villagers to describe the frequently used route. The farmers identified these two farms as the worst affected by elephant crop raids and were unanimously chosen by the group for the trials.

To verify this local knowledge of elephant movements through the community, Save the Elephants' (STE) research team monitored for us a notorious crop-raiding 
bull, Genghis Khan, through the area using data from his Global System for Communication (GSM) satellite tracking collar (made by African Wildlife Tracking). By continuously downloading his hourly GPS movements onto Google-Earth maps using STE's tracking software (Wall, 2007), we were able to ground-truth his movements using both aerial searches and a ground tracking team for close observations.

To the east of the elephant corridor, Farm A was chosen by the group to trial the beehive fence. On the west of the corridor, 466 m away, Farm B was designated a 'control' farm without a beehive fence. Both farms were approximately 2 acres and grew the same intercropped species of maize, potatoes and beans with a few scattered sorghum plants. Only two farms were used during this pilot trial to minimize any potential risk by bees to the farming group and to test out the new, untested design and responses from the group before extending the trial to other crop-raided farms.

Nine used but empty traditional log beehives were deployed in the form of an 'L' shape beehive fence along
$90 \mathrm{~m}$ of Farm A's northern boundary cutting off all the entrance routes frequented by raiding elephants. The field researcher introduced the technical design of the fence but the resulting final structure incorporated key adjustments contributed from group members' ideas (Fig. 1). The fence was deployed on the outer edge of a 10-m buffer zone around the crops to avoid any conflict between foraging bees and the farmer's daily activities with his crops. The rest of Farm A was protected by a neighbouring farm on the east, a strong hedge on the west and Farmer A's house to the south. With the help of twelve people, the fence took 2 days to build using twenty kerosene-treated poles, $200 \mathrm{~m}$ of plain fencing wire, $50 \mathrm{~m}$ of thin thatching wire, 2-inch and 4-inch nails, and $1 \mathrm{l}$ of wood preservative. The beehive fence was completed in July 2007 before peak crop harvest season of August-September, but lack of occupancy meant that unoccupied hives were used for this trial.

The farmers identified two indicators that would help them decide if the beehive fence was a success or not. These were; (i) elephants should be kept away from

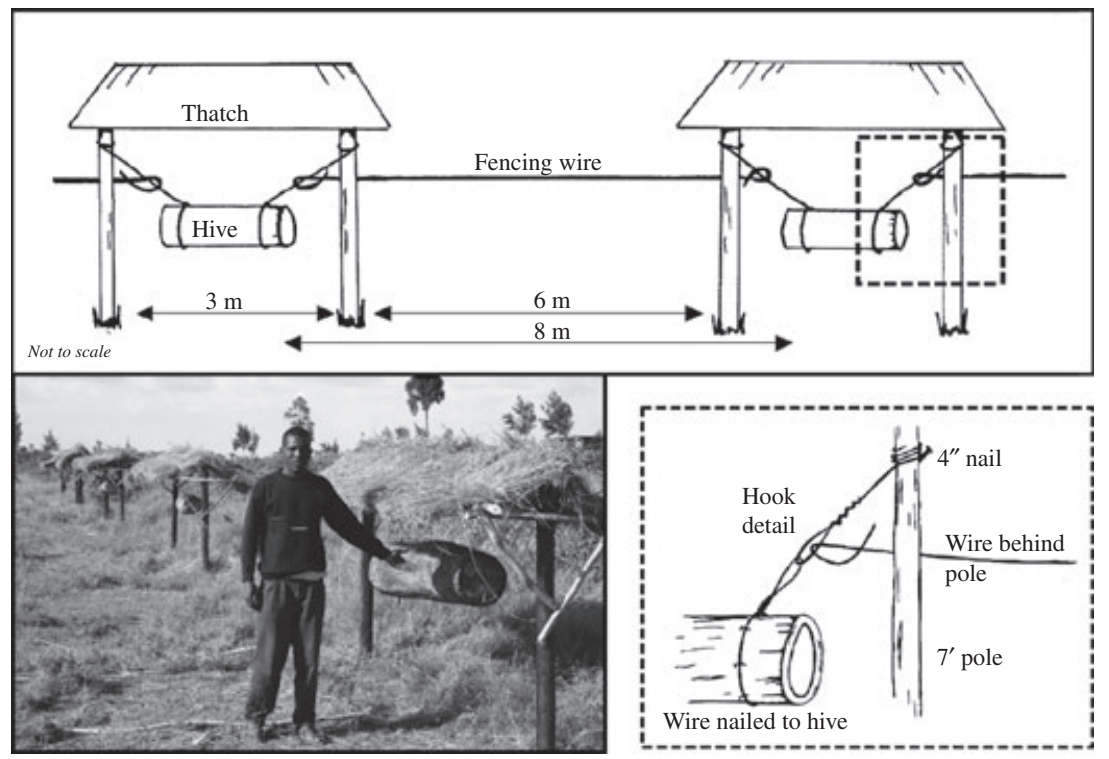

Fig 1 Beehive fence design. The fence is constructed with log beehives hung under small thatched roofs. The huts are spaced $6 \mathrm{~m}$ apart allowing the hives to be spaced $8 \mathrm{~m}$ apart. An elephant walking between huts will be less than $4 \mathrm{~m}$ to the nearest hive, the minimum distance elephants in the study area approached solitary beehives. The beehives swing freely, suspended by tightly secured fencing wire to the top of the seven foot poles. Each hive is linked to each other with strong, taut, fencing wire that hooks to the centre of the permanent wire of each hive and is, crucially, behind the upright poles on the crop side of the fence. An intruding elephant trying to enter the field will avoid the complex solid structure of the beehuts and will be channelled between them. As the elephant tries to push through the thighhigh wire, it causes the attached beehives to swing violently, thereby disturbing and releasing the bees to irritate or sting the elephant. However, if forced, the interlinking wire will break away before the beehive is pulled down. This also prevents elephants being trapped inside the farm as they can break out without damaging the hives. To prevent honey badger attacks, nail a 60-70 cm circular strip of iron sheet half way up the wooden post 
damaging or eating the crops and (ii) the fence should be easy and cheap to maintain. We identified several additional indicators that were important in defining the success of the trial. These indicators were; (i) identifying patterns of elephant movement behaviour around the beehive fence structures, (ii) identifying positive responses from the farmers and (iii) realistic set-up costs of the beehive fence to ensure it could be a financially appropriate technology for other poor communities. Before encouraging investment in new technologies, such indicators can be vital when assessing the likelihood of uptake.

The farmers recorded crop-raiding events using simple data sheets, clearly explained during a training session. Farmer A recorded the number of elephants breaking through to crop raid on his farm by noting the raid time, herd composition (when able) and movement pattern in and out of the farm. Farmer A sat up at his house with periodic checks on his crops leaving the beehive fence as his first defence. However, once on his land, Farmer A was freely available to chase the elephants away using whatever deterrent tactics he liked. Farmer B, without the beehive fence, also gathered daily data on the raid time and number of elephants successfully raiding but he also managed to record the number of elephants approaching his farm that were successfully scared away by his traditional deterrent tactics (personal vigilance, noise, fire, dogs). These data enabled us to monitor elephant movement behaviour and compare variation in crop raids between the two farms over the same 6-week period of peak crop harvest time.

To assess farmer perception of the beehive fence, the field researcher stimulated conversation about the progress of the project with both individuals and the group with all comments and actions observed during these weekly discussions recorded in a notebook. This resulting rapport enabled free flowing ideas and discussion about the beehive fence design and application.

\section{Results}

The movement of crop-raiding elephants throughout the community was verified from monitoring Genghis Khan's GPS tracking data over the same crop-raiding season. During the study, he was observed crop raiding by several farmers and photographed from the air by IDH and by LK on the ground in the centre of a herd of eighteen bull elephants coming back from crop raids in Ex-Erok. Dung from the herd was densely littered with bean husks and maize stalks. His GPS movements closely matched the consensus map of elephant movements drawn up by the group.

After the 6-week trial period, the data from both the elephant movements and the farmer's perceptions of elephant raids were studied in the context of each previously identified indicator. The evaluating indicators (cost, effectiveness, efficiency and perception) are briefly discussed.

\section{Costs and ease of fence maintenance}

The economics of the fence are an important indicator towards success or failure of the concept. Initial set-up costs will vary locally but need to include funds for: (i) the hive, (ii) a thatched roof for shade, (iii) two sturdy poles to carry hive and roof and (iv) stiff wiring to hang the hive and connect it with its neighbours. Often it will be possible to defer, or share, costs with a small local or national honey trader. During the trial, our beehive fence suffered four raids when elephants broke through the fencing wire and successful entered the farm. The wire did not break, nor did it bring down the beehives on either side so the farmer was able to simply clip the wire back into place ready for the following night. During the 6 weeks, there were minor repairs to the bee huts that could all be catered for from local resources at no cost (e.g. grass for thatching) or a small expense (e.g. a few nails). The fence was inspected every morning but this took away little time from the farmers' other daily chores. This suggests that a beehive fence, once erected, requires little maintenance. Of course, this will change when hives are occupied and especially when they are full of honey. Indeed, honey sales can potentially recover the cost of the hives reasonably quickly and provide a tangible incentive for maintaining the entire fence line structure. Costs for the beehive fence based on using traditional log beehives were approximately US\$315 per 100 m. In Kenya, 1 kg of honey can sell for US\$2 and each traditional log hive has the potential to generate two to three annual harvests of 7-10 kgs per harvest. Upgrading log beehives to the more productive Kenyan Top Bar (KTB) hives would generate more income, particularly if a queen excluder is fitted to separate the valuable honey from brood (Jones, 1999).

\section{Effectiveness as deterrent}

Over the 6-week study period, the two focal farms experienced twenty successful crop raids involving 133 elephants. Farm A, with the beehive fence, experienced seven 


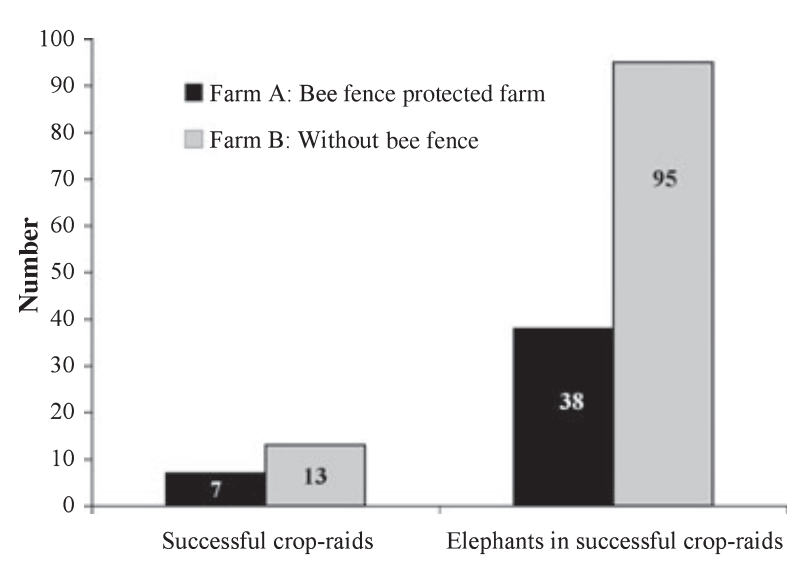

Fig 2 Variation in crop raiding incidents during the 6-week trial. Farm A, protected by the beehive fence, experienced $86 \%$ fewer successful raids and $150 \%$ fewer raiding elephants than control Farm B

successful raids involving 38 elephants. Farm B experienced thirteen raids ( $86 \%$ more than Farm A) involving 95 invading elephants $(150 \%$ more than Farm A; $X^{2}=P<0.001$, df 1) (Fig. 2). In addition, Farmer B recorded a further 71 elephants in eight failed raid attempts that he prevented from entering his farm using his traditional deterrent tactics. In total Farm B had 21 attempted raids by 166 elephants during the 6-week trial, all of which occurred less than 500 m from Farm A. Most notably, by the end of the harvest season, Farm B had almost no crops to harvest, with the farmer estimating that about $90 \%$ of his harvest had been destroyed or eaten by elephants, whereas Farmer A was able to harvest relatively successfully collecting a variety of sorghum, beans, potatoes and maize. This suggests that the fence was at least partially successful in deterring elephants.

\section{Efficiency of beehive fence}

Within Farm A, there were ten clustered events where elephants broke into the farm within the seven successful raids. Of these ten inbound events, four occurred between the beehuts pulling down the fencing wire and six occurred by elephants walking around the beehuts to make new entrances into the farm above the beehive fence line breaking down the hedge. Once inside Farm A, there were fourteen clustered events where elephants broke out of the Farm (either naturally or chased away by Farmer A). Of these fourteen outbound events, twelve occurred between the beehive huts and two occurred outside the beehive fence line. Essentially, the beehive fence did not pose a trap to the elephants inside the farm once scared off the land by Farmer A. There was no correlation in dates between all 21 attempted events on Farm B (either deterred visit or successful raid) and the seven successful raids on Farm A. Elephants deterred from one farm do not necessarily move on to raid the next closest farm.

\section{Perception by farmers}

Social responses and attitudes to the project were consistently very positive throughout the trial. The following key observations were made:

1. A consistent number of group members turned up to each meeting with a slow increase from eight to twelve. Although overall group membership increased from seventeen to 24 as word of the trial spread, over half these listed group members remained curious spectators rather than integrated participants. A scout from Dr Graham's 'Darwin-Cambridge Laikipia Elephant Research Project' commented about Farm A verbatim 'You can't compare his farm to the others now. He still has crops and the others are all finished by elephants.'

2. After the main 6-week-study period, Farmer A extended (at his own initiative and cost) the beehive fence with two more hives to cover a new elephant entrance site above the beehive fence.

3. All attending members of the beekeeping group expressed a desire to have a similar fence around their farm listing the potential benefits of the fence as (i) deterring elephants, (ii) honey production, (iii) improved security from cattle rustlers and (iv) improved sleeping patterns inside the house rather than outside in a corner of the field. 4. Members of the group discussed the risks of the fence, i.e. increased stings (danger) for children and livestock fatalities from bee attacks. It was agreed that these risks were outweighed by the daily risk of being trampled by an elephant and hunger because of complete harvest destruction.

5. The main disincentive for starting construction was (i) cost of materials and (ii) knowledge that a governmentsponsored electric elephant fence was about to be constructed to protect the community from future elephant raids (this was completed by February 2008).

\section{Discussion}

To conduct this pilot study, we used our predesigned technology (the beehive fence) that was field tested under 
'real life' conditions with the end users to assess effectiveness and adoption potential. Our participatory study helped to generate a sense of participant ownership and enabled the evaluation of genuine responses and attitudes to the introduced technology by both scientists and farmers.

The effectiveness of the beehive fence was remarkable as there were fewer raids and a significantly lower number of elephants in successful raids on the protected farm compared with the nearby control farm, which suffered severe (and apparently typical) damage from crop-raiding elephants during the trial period.

Equally encouraging were the positive responses from the farmers towards the concept of a beehive fence. Although there was a recognized risk from increasing the bee population so close to their living quarters, the risk was outweighed by the benefits of the fence for deterring destructive elephants plus the long-term potential of generating a sustainable income through the sale of bee products. Farmers believed that the beehive fence also protected them from cattle rustlers and they predicted being able to spend more time in the house at night.

The sample size (one experimental and one control farm) was small and variables such as soil type, exact hours of vigilance, crop density and variation in outer boundary defences (e.g. thickness of low protective hedges) around the two farms were not quantifiably measured. Despite these possible variations, the outcome was robust with the experimental farm attracting fewer elephant raiders and consequently growing more produce. Moreover, the participants in the experiment were convinced that the deterrent worked and decided, on their own and with their own funds, to continue with beekeeping through construction of more hives to extend the fence and the planting of nectar producing vegetation. Hence, overall, we consider this a successful pilot trial of a simple design for a guardian-bee elephant deterrent in an area of smallscale farms. Interestingly, as none of the hives was occupied during the trial, the deterrent must have been due to either (or both) (i) the image or smell remembered by the elephants of past negative experiences with occupied hives and/or (ii) the complex physical, moving barrier of the wires and swinging hives. In the light of other experiments (Vollrath \& Douglas-Hamilton, 2002; King et al., 2007; King et al., in prep), we suspect that the outcome of this study was largely because of previous 'anti-bee' conditioning of the elephants.

As the site was fenced against elephants shortly after the experiments, we could not follow up our pilot trials with more farms but instead started a major beehive fence experiment (with 60 farms) using KTB hives in another part of Kenya. Although this experiment has been taken up with comparable enthusiasm by its participants (which unlike the Ex-Erok farmers had no prior experience with bee keeping), all those farms were devastated by the $2008 / 2009$ drought resulting in 100\% loss in crops and consequently a total lack of elephant raids. As word of our Ex-Erok pilot study spread, more farmers and researchers begun to question us about the concept, hence we decided to publish its details in order to allow others to independently begin rigorously testing our thesis now rather than delay by a few more years, with possibly detrimental socio-economic consequences.

\section{Acknowledgements}

We thank the Office of the President of the Republic of Kenya and Kenya Wildlife Service for permission to conduct this research and we are grateful to Dr Max Graham and his scout J. Wahome for introduction to the field site. The British ESRC/NERC supported LK with a studentship at the University of Oxford. On behalf of Save the Elephants, we thank the Disney Worldwide Conservation Fund for generous fieldwork support and Safaricom and Vodafone Foundations for supporting the development of our elephant tracking software capabilities. We thank the Mwireri Beekeepers Group, particularly Ephrahim Maina and Felix Mathenge (Farmers A and B) and L. Lepuiyapui for their assistance during the study.

\section{References}

Balfour, D., Dublin, H.T., Fennessey, J., Gibson, D., Niskanen, L. \& Whyte, I.J. (2007) Review of Options for Managing the Impacts of Locally Overabundant African Elephants. IUCN, Gland, Swizerland.

BARNES, R.F.W. (1996) The conflict between humans and elephants in central African forests. Mammal Rev. 26, 67-80.

BradBear, N. (2002) Beekeeping and Sustainable Livelihoods. Strengthening Livelihoods Exploring the Role of Beekeeping in Development. Bees for Development, Monmouth, UK.

Douglas-Hamilton, I., Krink, T. \& Vollrath, F. (2005) Movement and corridors of African elephants in relation to protected areas. Naturwiss 92, 158-163.

Franzel, S., Scherr, S.J., Coe, R., Cooper, P.J.M. \& Place, F. (2002) Trees on the Farm. Assessing the Adoption of Agroforestry Practices in Africa. (Ed. S. FranzeL and S. J. SCHERR). CAB International in association with ICRAF. 
Graham, M.D. (2007) Coexistence in a land use mosaic? Land use risk and elephant ecology in Laikipia District, Kenya. $\mathrm{PhD}$ thesis, University of Cambridge, Cambridge, U.K.

GRAHAM, M.D. \& OCHIENG, T. (2008) Uptake and performance of farm-based measures for reducing crop raiding by elephants Loxodonta africana among smallholder farms in Laikipia District, Kenya. Oryx 42, 76-82.

Heldin, J., Bellon, M.R., Badstue, L., Dixon, J. \& La Rovere, R. (2008) Increasing the Impacts of Participatory Research. Exp. Agric. 44, 81-95.

HoARe, R.E. (2000) African elephants and humans in conflict: the outlook for coexistence. Oryx 34, 34-38.

JoNes, R. (1999) Beekeeping as a Business. International Bee Research Association, Published by Commonwealth Secretariat, London.

KAPOOR, I. (2001) Towards participatory environmental management? J. Environ. Manage. 63, 269-279.

King, L.E., Douglas-Hamiton, I. \& Vollrath, F. (2007) African elephants run from the sound of disturbed bees. Curr. Biol. 17, R832-R833.

Newmark, W.D., Manyanza, D.N. \& Gamassa Deo-Gratias, M. (1994) The conflict between wildlife and local people living adjacent to protected areas in Tanzania: human density as a predictor. Conserv. Biol. 8, 249-255.

OMONDI, P., BITOK, E. \& KAgIRI, J. (2004) Managing humanelephant conflicts: the Kenyan experience. Pachyderm 36, 80-86.

Osborn, F.V. \& PARKer, G. (2002) Elephant/Human Conflict around the Luangwa National Parks, Zambia. Consultancy Report for WWF/SARPO. Harare, Zimbabwe.

OSBORN, F.V. \& PARKER, G. (2003) Towards an integrated approach for reducing the conflict between elephants and people: a review of current research. Oryx 37, 80-84.

RaINA, S.K. (2000) The Economics of Apiculture and Sericulture Modules for Income Generation in Africa. IBRA Press, UK.

Vollrath, F. \& Douglas-Hamilton, I. (2002) African bees to control African elephants. Naturwiss 89, 508-511.

WALL, J.G. (2007) Save the Elephants Annual Report 2006-2007. Save the Elephants, Nairobi, Kenya.

(Manuscript accepted 26 March 2009)

doi: 10.1111/j.1365-2028.2009.01114.x 